\section{A rare neuro-ophthalmological phenomenon: Marcus Gunn jaw winking ptosis}

Thirumalaivasan Dhasakeerthi MBBS ${ }^{1}$, Paul Drake $\mathrm{MD}^{2}$, Akilandeswari Aravindhan $\mathrm{MBBS}^{2}$, Aravindhan Veerapandiyan $\mathrm{MD}^{2}$

${ }^{1}$ Department of Neurology, University of Tennessee Health Science Center, Memphis TN

${ }^{2}$ Division of Neurology, Department of Pediatrics, University of Arkansas for Medical Sciences, Arkansas Children's Hospital, Little Rock, AR

Patient is a 13 year old girl with right upper eyelid ptosis since birth and elevation of her right upper eyelid with mouth opening, lateral jaw movements, and tongue protrusion. Marcus Gunn jaw winking ptosis is extremely rare occurring in 2-13\% of patients with congenital ptosis. It is due to aberrant neuronal connection between motor fibers of trigeminal nerve and superior division of oculomotor nerve that innervates levator palpebrae superioris. ${ }^{1}$ Acquired forms may develop after eye surgery, trauma, syphilis, and pontine tumors. It is mostly sporadic but can be associated with amblyopia, strabismus, and anisometropia ${ }^{2}$.

\section{$\underline{\text { Video } 1}$}

\section{$\underline{\text { Video } 2}$}

\section{Corresponding author:}

Aravindhan Veerapandiyan, MD

Arkansas Children's Hospital

Office phone: 501-364-1850

Fax: 501-364-6077

aveerapandiyan@uams.edu

\section{References}

1. Gunn RM. Congenital ptosis with peculiar associated movements of the affected lid. Trans Ophthalmol Soc UK. 1883;3(1):283.

2. Pratt SG, Beyer CK, Johnson CC. The Marcus Gunn phenomenon. A review of 71 cases. Ophthalmology. 1984;91:27-30.

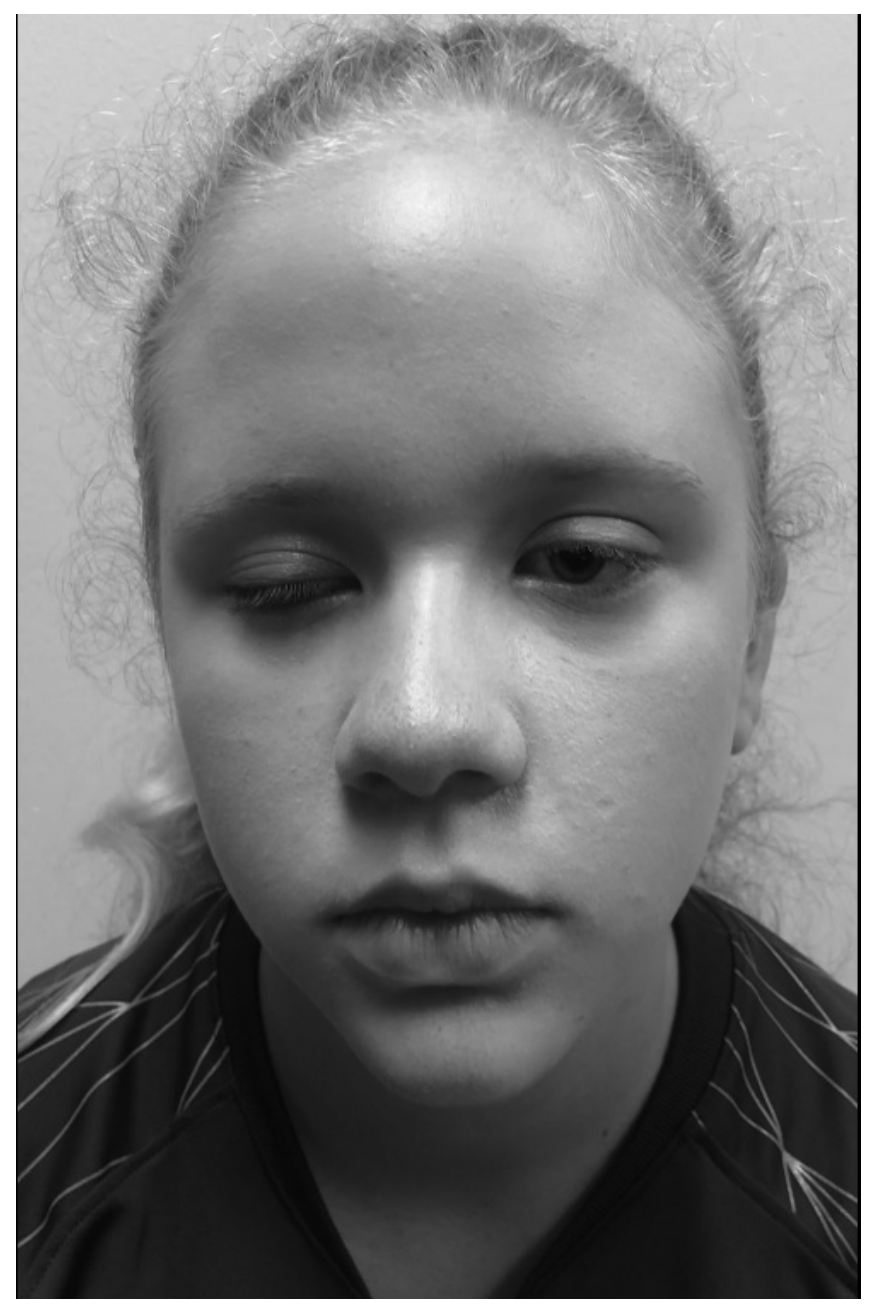

Figure. Still from video of 13 year old girl with Marcus Gunn jaw winking ptosis right upper eyelid. Elevation of right upper eyelid noted with mouth opening and lateral jaw movements (video 1) and tongue protrusion (video 2). 